\title{
Translation and Indigenous Languages
}

Tusaaji recognizes the resurgence of Indigenous Peoples of the Americas throughout our common hemisphere, where, to varying degrees, Indigenous voices can not only be heard and read echoing through the four main Euro-American languages as they are spoken in the Americas, but also, importantly, in the approximately one thousand Indigenous languages, whose narratives, verbal art, and epistemologies/ontologies have survived and are flourishing after half a millennium of European and settler-state colonization. The quantity and quality of the textual flows and translation activity between and within the Indigenous worlds, and between the Indigenous and the nonIndigenous worlds is growing every year.

Tusaaji proposed in its fourth issue to offer a space to explore topics relating to translation and Indigenous languages of the Americas. We invited papers written in Spanish, Portuguese, French, English, or any Indigenous language of the Americas with the aim of engaging the theme of translation and Indigenous languages from a hemispheric focus. We sought, and obtained, contributions from various fields, perspectives, contexts, and historical periods. The reader will find articles addressing issues such as Indigenous translation events or practices, Indigenous decolonial critiques and narrative praxis, Indigenous knowledges, epistemic flows, epistemologiesin-contact, counterhegemonic linguistic practices, contemporary Indigenous cultural production, and others.

We realize that this issue has barely scratched the surface of this important field, and we hope that papers on indigenous themes will become a frequent presence in future issues of Tusaaji.

lan Martin, Guest editor. 